Meta

Journal des traducteurs

Translators' Journal

\title{
Directionality in Signed Language Interpreting
}

\section{Jihong Wang et Jemina Napier}

Volume 60, numéro 3, décembre 2015

URI : https://id.erudit.org/iderudit/1036141ar

DOI : https://doi.org/10.7202/1036141ar

Aller au sommaire du numéro

\section{Éditeur(s)}

Les Presses de l’Université de Montréal

\section{ISSN}

0026-0452 (imprimé)

1492-1421 (numérique)

Découvrir la revue

Citer cet article

Wang, J. \& Napier, J. (2015). Directionality in Signed Language Interpreting. Meta, 60(3), 518-541. https://doi.org/10.7202/1036141ar

\section{Résumé de l'article}

Cette étude à méthodologie mixte examine les effets du sens de traduction et de l'âge d'acquisition de la langue des signes sur les performances d'un groupe d'interprètes professionnels simultanés anglais/Auslan (langue des signes australienne), comprenant des signeurs à la fois natifs et non natifs. Chaque participant a été invité à interpréter en simultanée une série de présentations de l'anglais vers l'Auslan et vice versa, puis à participer à un bref entretien semi-directif. Contrairement aux conclusions d'une étude similaire, aucune différence notable n'a été constatée entre les performances des interprètes signeurs natifs de l'Auslan vers l'anglais et leurs performances de l'anglais vers l'Auslan, ce qui suggère que le sens de traduction n'affecte pas les performances des interprètes bilingues dits « équilibrés ». Bien que la même conclusion ait été observée pour les interprètes signeurs non natifs, l'étude révèle que ceux-ci doivent toutefois continuer à améliorer leur compétence en langue des signes (L2). Par ailleurs, malgré la similitude entre les performances globales des signeurs natifs et celles des signeurs non natifs dans les deux sens de traduction, l'étude a démontré que, dans le cas de l'interprétation de l'anglais vers l'Auslan, les performances des signeurs natifs étaient nettement supérieures à celles des signeurs non natifs sur deux points : les aspects du texte cible et la qualité d'élocution. Cette observation suggère également que les signeurs non natifs doivent continuer à améliorer leur compétence en langue des signes (L2). Une analyse des données qualitatives issues des entretiens révèle cependant que chaque sens de traduction était perçu par les interprètes professionnels comme posant des défis distincts.
Ce document est protégé par la loi sur le droit d'auteur. L’utilisation des services d'Érudit (y compris la reproduction) est assujettie à sa politique d'utilisation que vous pouvez consulter en ligne.

https://apropos.erudit.org/fr/usagers/politique-dutilisation/ 


\title{
Directionality in Signed Language Interpreting
}

\author{
JIHONG WANG \\ The University of Queensland, Brisbane, Australia \\ jihong.wang@mq.edu.au

\section{JEMINA NAPIER} \\ Heriot-Watt University, Edinburgh, United Kingdom \\ j.napier@hw.ac.uk
}

\section{RÉSUMÉ}

Cette étude à méthodologie mixte examine les effets du sens de traduction et de l'âge d'acquisition de la langue des signes sur les performances d'un groupe d'interprètes professionnels simultanés anglais/Auslan (langue des signes australienne), comprenant des signeurs à la fois natifs et non natifs. Chaque participant a été invité à interpréter en simultanée une série de présentations de l'anglais vers l'Auslan et vice versa, puis à participer à un bref entretien semi-directif. Contrairement aux conclusions d'une étude similaire, aucune différence notable n'a été constatée entre les performances des interprètes signeurs natifs de l'Auslan vers l'anglais et leurs performances de l'anglais vers l'Auslan, ce qui suggère que le sens de traduction n'affecte pas les performances des interprètes bilingues dits «équilibrés». Bien que la même conclusion ait été observée pour les interprètes signeurs non natifs, l'étude révèle que ceux-ci doivent toutefois continuer à améliorer leur compétence en langue des signes (L2). Par ailleurs, malgré la similitude entre les performances globales des signeurs natifs et celles des signeurs non natifs dans les deux sens de traduction, l'étude a démontré que, dans le cas de l'interprétation de l'anglais vers l'Auslan, les performances des signeurs natifs étaient nettement supérieures à celles des signeurs non natifs sur deux points: les aspects du texte cible et la qualité d'élocution. Cette observation suggère également que les signeurs non natifs doivent continuer à améliorer leur compétence en langue des signes (L2). Une analyse des données qualitatives issues des entretiens révèle cependant que chaque sens de traduction était perçu par les interprètes professionnels comme posant des défis distincts.

\section{ABSTRACT}

This mixed methods study investigated the effects of directionality (language direction) and age of signed language acquisition on the simultaneous interpreting performance of professional English/Auslan (Australian Sign Language) interpreters, who comprised native signers and non-native signers. Each participant interpreted presentations simultaneously from English into Auslan, and vice versa, with each task followed by a brief semi-structured interview. Unlike a similar study, results reveal no significant differences between the native signers' English-to-Auslan simultaneous interpreting performance and their Auslan-to-English simultaneous interpreting performance, suggesting that balanced bilingual interpreters are free from the rule of directionality. Although this finding held true for the non-native signers, results indicate a need for the non-native signers to continue to enhance their signed language (L2) competence. Furthermore, although the native signers were similar to the non-native signers in overall simultaneous interpreting performance in each language direction, the native signers were significantly superior to the non-native signers in both the target text features and delivery features of Englishto-Auslan simultaneous interpreting performance. These findings also suggest that the non-native signers need to further improve their signed language (L2) proficiency. Nevertheless, an analysis of the qualitative interview data reveals that the professional interpreters perceived distinct challenges that were unique to each language direction. 


\section{MOTS-CLÉS/KEYWORDS}

interprétation en langue des signes, performances en interprétation simultanée, sens de traduction, signeurs natifs, signeurs non natifs

signed language interpreting, simultaneous interpreting performance, directionality (language direction), native signers, non-native signers

\section{Introduction}

Directionality refers to interpreting from a non-native language (L2) into a native language $(\mathrm{L} 1)^{1}$ or vice versa, in simultaneous or long consecutive mode, when the source language discourse is monologic (Napier, Rohan et al. 2005). Regarding spoken language conference interpreting, ${ }^{2}$ the International Association of Conference Interpreters (AIIC) and international institutions have traditionally favoured L2-to-L1 simultaneous interpreting (Gile 2005; Martin 2005; Pöchhacker 2004; Seleskovitch 1978). Given the dearth of empirical evidence, interpreting scholars and educators have started to re-examine and even challenge this predominant norm of directionality in spoken language conference interpreting (see Godijns and Hinderdael 2005; Hild 2006). The reality is that L1-to-L2 simultaneous interpreting is widely practised by spoken language interpreters on the private market (Martin 2005; Pavlović 2007; Pöchhacker 2004) partly due to economic reasons, a lack of interpreters of particular language pairs, and the proliferation of English as a lingua franca. Interpreters who are balanced bilinguals are ideal and free from the aforementioned rule of directionality because they work between two native languages (Denissenko 1989; Seleskovitch 1978). Nevertheless, balanced bilinguals are few and far between among spoken language interpreters.

Although spoken language interpreting and signed language interpreting are thought to share the same underlying cognitive processes, they differ essentially in language modality (Kellett Bidoli 2002; Metzger 2006; Napier, McKee et al. 2006/2010; Nicodemus and Emmorey 2013). Compared with spoken language interpreting, signed language interpreting is a younger profession (Napier 2011; Nicodemus and Emmorey 2013). Signed language interpreters work predominantly in community settings (for example, education, workplace, healthcare, court), but they also work at conferences occasionally (for example, World Federation of the Deaf Congresses, professional conferences, formal public events). For signed language interpreters, interpreting university lecture content aligns with conference interpreting because of the formal register of language, complex subject matter, and unidirectional communication (Napier 2002; Napier, Rohan et al. 2005). Signed language interpreters work predominantly in simultaneous mode without the need for acoustic separation from the speaker (Napier, McKee et al. 2006/2010), as there is no auditory interference between a spoken language and a signed language.

While some signed language interpreters are relatively balanced bilinguals who typically have signing deaf parents, the vast majority of signed language interpreters are unbalanced bilinguals who have a spoken language as their native language (L1) but learned a signed language as their non-native language (L2) later in life. Signed language interpreters work typically from a spoken language into a signed language (Napier 2011; Nicodemus and Emmorey 2013; Russell and Malcolm 2009), because signed language interpreting often occurs in situations where deaf signers rely on 
interpreting services in order to access information given by hearing speakers. That is, the majority of signed language interpreters work predominantly from their native language (L1, a spoken language) into their non-native language (L2, a signed language), contravening the established practice of spoken language conference interpreting mentioned earlier.

To date, very few studies have examined directionality effects on the actual interpreting performance of either spoken or signed language interpreters. The present study partially narrows this gap by investigating the effects of directionality and age of signed language acquisition on the simultaneous interpreting performance of professional Auslan (Australian Sign Language)/English interpreters. In order to contextualize the mixed methods research design of this study, it is useful to begin with a brief overview of the relevant literature.

\section{Background}

Directionality has been of interest to researchers in the linguistic sub-disciplines of bilingualism, psycholinguistics, and translation and interpreting studies. Some studies have examined directionality in lexical translation. Kroll and Stewart (1994) and de Bot (2000) found that bilinguals' L2-to-L1 word translation was faster than their L1-to-L2 word translation, with this asymmetry diminishing with increasing bilingual proficiency. However, Christoffels, De Groot et al. (2006) found that professional spoken language interpreters' L2-to-L1 word translation was as fast as their L1-to-L2 word translation. Regarding American Sign Language (ASL)/English interpreters with English as their native language (L1) and ASL as their non-native language (L2), Nicodemus (2011) found that expert interpreters' L2-to-L1 lexical translation was as accurate as their L1-to-L2 lexical translation, but that novice interpreters' L2-to-L1 lexical translation was significantly more accurate than their L1-to-L2 lexical translation. Given that lexical translation is a different process from interpreting, more attention will be given to the existing literature on directionality in spoken and signed language interpreting as well as on similarities and differences between native signers and non-native signers.

\subsection{Directionality in spoken language interpreting}

Language direction has long been a subject of debate among spoken language conference interpreting educators. Seleskovitch (1978: 100), the pioneer of the Paris school of thought, claims that "simultaneous interpretation can only be done properly into one's native language." This view is primarily because native language (L1) production is spontaneous, idiomatic, clear, and smooth, which therefore ensures that the users easily understand the interpreter's interpretation. By contrast, Denissenko (1989) of the former Soviet Union contends that simultaneous interpretation from L1 into L2 is more favourable, on the grounds that native language (L1) comprehension would ensure accuracy in interpretation. Due to a lack of empirical evidence, the two opposing views are largely based on personal experience, ideology, and tradition (Gile 2005). Both views appear to be oversimplified, because they focus on language competence only and they do not consider non-linguistic parameters that may have an impact on interpreting performance. 
Some researchers now look at the directionality issue from a broader perspective. Gile (2005) points out that interpreting performance depends on numerous factors such as the interpreter's language proficiency, familiarity with subject matter, working memory capacity, state of health, motivation, and professionalism. Gile therefore maintains that directionality effects on interpreting performance might be small or even negligible. In addition, Kalina (2005) argues that the question of which language direction results in a higher quality of interpreting performance should be addressed in specific terms such as language pair, type of conference, nationalities and cultural backgrounds of the speakers and the listeners, and language distribution. Seel (2005) asserts that research into directionality effects on interpreting performance should take into account parameters such as non-verbal discourse patterns of the source culture, working conditions, specific contextual and extralinguistic factors, the speakers and the listeners, subject matter, and cognitive demands on the interpreter. Similarly, Pavlović (2007) endorses that variables such as the directionality norm (that spoken language conference interpreters should interpret into their L1), interpreter education, and the interpreter's previous work experience may confound directionality effects on interpreting performance. All these variables may jointly influence simultaneous interpreting performance in each language direction, thus confounding or even offsetting directionality effects on simultaneous interpreting performance. Neither language direction is intrinsically easier than, or superior to, the other language direction (Kalina 2005; Martin 2005; Padilla 2005; Seel 2005).

Extensive survey research has concentrated on interpreters' feelings about directionality. Professional spoken language interpreters typically prefer, and feel more proficient in, L2-to-L1 interpreting and perceive L1-to-L2 interpreting to be more stressful and tiring (Bartłomiejczyk 2004; Choi 2008; Donovan 2004; 2005; Lim 2005; Martin 2005; Nicodemus and Emmorey 2013). Nonetheless, Al-Salman and Al-Khanji (2002) found that professional Arabic/English interpreters felt more comfortable working from Arabic (L1) into English (L2) than the other way around, which may be due to their insufficient mastery of Arabic (Gile 2005). It is worth noting that interpreters' directionality preferences are subjective and may be related to their personal and professional profile, age of L2 acquisition, self-perceived bilingual proficiency, language combinations, and interpreting experience (Bartłomiejczyk 2004).

Despite a large number of survey studies on interpreters' directionality preferences, few empirical studies have examined directionality effects on actual interpreting performance. Tommola and Laakso (1997) and Tommola and Helevä (1998) found that student interpreters' propositional accuracy in simultaneous interpretation was significantly affected by the delivery speed and linguistic complexity of the source text rather than by directionality. These findings support the aforementioned view of Gile (2005) that other factors rather than directionality may have a greater impact on simultaneous interpreting performance.

Nevertheless, results from student interpreters may not apply to professional interpreters. Daro, Lambert et al. (1996) found that 16 professional French/English interpreters ${ }^{3}$ made significantly more omissions when simultaneously interpreting difficult texts from L1 into L2 than vice versa. Chang and Schallert (2007) found that six professional Mandarin/English interpreters not only achieved significantly higher propositional accuracy but also made significantly fewer target-language-use errors (grammatical and lexical errors) when simultaneously interpreting from L2 (English) 
into L1 (Mandarin) than vice versa. By contrast, Chang and Schallert did not observe significant directionality effects on the propositional accuracy or the target-languageuse errors for another three professional Mandarin/English interpreters who had reported being dominant in English or being equally competent in both languages. These results indicate that interpreters' relatively balanced bilingual competence may mitigate directionality effects on their simultaneous interpreting performance. Further empirical research is needed to verify these findings.

\subsection{Directionality in signed language interpreting}

Although many studies have investigated directionality in spoken language interpreting, very few studies have explored the same topic in signed language interpreting. To date, three survey studies have examined the directionality preferences of signed language interpreters. Napier, Rohan et al. (2005) found that certified Auslan/English interpreters preferred working from English (L1) into Auslan (L2), with less experienced interpreters expressing a stronger preference for this language direction. Similarly, Xiao and Yu (2009) found that signed language interpreters in China predominantly considered it more difficult to interpret into Chinese (L1) than into Chinese Sign Language (L2). More recently, Nicodemus and Emmorey (2013) found that ASL/English interpreters not only preferred but also felt more proficient working from their L1 (English) into L2 (ASL). As in Napier, Rohan et al.'s (2005) study, novices reported a stronger preference for interpreting from L1 into L2 (English-to-ASL) than experts did, suggesting that extensive interpreting experience may result in equal preference for L2-to-L1 and L1-to-L2 interpreting. Furthermore, Nicodemus and Emmorey found that ASL/English interpreters who were native signers largely reported no directionality preferences, indicating that balanced bilingual proficiency may mitigate directionality preferences.

Interpreters' directionality preferences may not match their actual interpreting competence. Nicodemus (2011), in the study mentioned earlier, investigated directionality effects on the simultaneous interpreting performance of 32 ASL/English interpreters, all of whom had English as L1 and learned ASL (L2) in adulthood. Her participants comprised two groups: 16 experts who were certified interpreters with over 10 years of interpreting experience, and 16 novices who were pre-certified interpreters with less than five years of interpreting experience. Regarding the experts, Nicodemus found no significant directionality effects on the accuracy, fluency, speed, or prosody of their simultaneous interpreting performance. The novices scored significantly higher in terms of accuracy, speed, and prosody when simultaneously interpreting from ASL into English (L2-to-L1) than vice versa; however, they scored significantly lower in terms of fluency when simultaneously interpreting from ASL into English (L2-to-L1) than the other way around. It is important to note that although novices typically preferred to interpret from L1 (English) into L2 (ASL) (Nicodemus and Emmorey 2013), they actually performed significantly better when interpreting from L2 (ASL) into L1 (English) (Nicodemus 2011).

Moreover, van Dijk, Boers et al. (2011) explored the effects of directionality and age of signed language acquisition on the simultaneous interpreting performance of 25 experienced Sign Language of the Netherlands (SLN)/Dutch interpreters. The participants consisted of 10 native signers and 15 non-native signers. Van Dijk, Boers 
et al. found that the native signers' Dutch-to-SLN simultaneous interpreting performance was significantly better than their SLN-to-Dutch simultaneous interpreting performance. By the same token, the non-native signers' Dutch-to-SLN (L1-to-L2) simultaneous interpreting performance was significantly superior to their SLN-toDutch (L2-to-L1) simultaneous interpreting performance. Participants' inferior performance on SLN-to-Dutch simultaneous interpreting was attributed to the following two reasons:

- In real life, they had less experience interpreting from SLN into Dutch than vice versa;

- They may have encountered SLN comprehension problems due to extensive linguistic variation in SLN.

Furthermore, van Dijk, Boers et al. found that the native signers were similar to the non-native signers in their overall simultaneous interpreting performance (combining Dutch-to-SLN and SLN-to-Dutch simultaneous interpreting performances), in part due to the small sample size of the study. Given that the native signers were compared with the non-native signers in terms of their overall simultaneous interpreting performance, it remained unclear whether the two groups differed in their performance in each language direction, which merits further research.

The experts (non-native signers) in Nicodemus's (2011) study had a similar amount of interpreting experience to the non-native signers in van Dijk, Boers et al.'s (2011) study; however, these two groups exhibited different directionality effects on their simultaneous interpreting performance. The different results between the SLN/ Dutch interpreters and the ASL/English interpreters might reflect greater lexical variation in the SLN data compared with the ASL data. Future research is needed to identify the reasons for such divergent findings. In terms of evaluating accuracy in interpretation, one concern is that both studies conducted the evaluation using selected sentences from the source text instead of using the entire source text. Even though the selected sentences were accurately transferred, the entire source text may still be inadequately interpreted. Further empirical research therefore is needed to shed more light on directionality in signed language interpreting.

\subsection{Native signers versus non-native signers: Does it matter?}

Given that signed language interpreters consist of native signers and non-native signers, one may wonder whether the two groups differ in their interpreting performance. Apart from van Dijk, Boers et al.'s (2011) study, only the following two studies have explored the similarities and differences between native signers and non-native signers in actual interpreting performance.

Napier (2006) required two professional Auslan/English interpreters (a native signer and a non-native signer) to interpret university lectures from English into Auslan (a different lecture for each interpreter but on a similar topic). She noted that the native signer used mouthing and fingerspelling appropriately and effectively in the English-to-Auslan interpretation, while the non-native signer exhibited more English interference and used more marked mouthing and fingerspelling in the English-to-Auslan interpretation (for example, in terms of inclusion of function words). Napier suggested that the non-native signer might still be thinking in English rather than in Auslan during the English-to-Auslan interpreting, which may have 
affected their Auslan output. This speculation on the part of Napier is consistent with Nicodemus and Emmorey's (2013) view that novice interpreters may easily default to fingerspelling and transcoding (literal word-for-sign translation) when interpreting from a spoken language into a signed language.

Moreover, Goswell (2011) investigated the use of role shift ${ }^{5}$ in English-to-Auslan interpretations produced by four accredited Auslan/English interpreters (two native signers and two non-native signers). She found that the interpreters were highly variable in the amount of role shift produced, with no clear advantage on the part of the native signers. Thus, more research is needed to provide further insight into how important the nativeness effect may be in relation to accuracy in interpretation.

In sum, much evidence shows that spoken language interpreters often prefer to interpret from their non-native language (L2) into their native language (L1); in stark contrast, signed language interpreters typically prefer to interpret from their L1 (a spoken language) into their L2 (a signed language). It is important to note that interpreters' directionality preference may not align with their actual interpreting competence. To date, very few empirical studies have explored directionality effects on the actual interpreting performance of either spoken or signed language interpreters. Hence, the current mixed methods study makes a contribution to the body of literature reviewed thus far, as it aims to investigate the effects of directionality and age of signed language acquisition on the simultaneous interpreting performance of professional Auslan/English interpreters.

\section{Method}

\subsection{Participants}

Due to its focus on conference level signed language interpreting in Australia, this study required that participants be professional level Auslan/English interpreters qualified by the National Accreditation Authority for Translators and Interpreters (NAATI). ${ }^{6}$ A total of 31 NAATI-accredited professional level Auslan/English interpreters self-selected to participate in the study, consisting of 14 native signers and 17 non-native signers. The native signers acquired both Auslan and English from birth - the first from their signing deaf parents, the second through interaction with the surrounding hearing population. ${ }^{7}$ The native signers were thus considered to be native users of both English and Auslan (balanced bilinguals). According to participant self-reports, the non-native signers acquired English from birth from their hearing parents; they often had no family connections to the Australian Deaf Community, but started to learn Auslan at or after age 10 by receiving formal education in Auslan and/or associating with deaf signers through work or social networks. The non-native signers were thus considered to be unbalanced bilinguals with English as their native language (L1) and Auslan as their non-native language (L2). Data were collected in four major cities across Australia: Sydney, Melbourne, Brisbane, and Perth.

Participants' demographic and professional data are summarized in Table 1 . The majority of participants were female (87\%), which is representative of the working population of Auslan/English interpreters (see Bontempo and Napier 2007; Napier and Barker 2003). The native signers were similar to the non-native signers in age 
and interpreting experience. Compared with the native signers, the non-native signers received more general education and interpreter education. Although participants generally expressed no directionality preference, they reported practising Englishto-Auslan interpreting more often than Auslan-to-English interpreting.

TABLE 1

\section{Professional interpreters' demographic and professional data}

\begin{tabular}{|l|c|c|}
\hline Demographic/professional profile & $\begin{array}{c}\text { Native signers } \\
(\mathrm{N}=14)\end{array}$ & $\begin{array}{c}\text { Non-native signers } \\
(\mathrm{N}=17)\end{array}$ \\
\hline Female vs. male & 11 vs. 3 & 16 vs. 1 \\
\hline Mean age, in years (SD) & $40(14)$ & $40(9)$ \\
\hline Mean age of acquiring Auslan, in years (SD) & $0(0)$ & $19(6)$ \\
\hline Interpreters with a BA or MA degree (\%) & $6(43 \%)$ & $14(82 \%)$ \\
\hline Trained vs. untrained interpreters & 9 vs. 5 & 14 vs. 3 \\
\hline Full-time vs. part-time interpreters & 10 vs. 4 & 10 vs. 7 \\
\hline Mean hours of paid interpreting per month (SD) & $91(60)$ & $79(55)$ \\
\hline Mean years of interpreting experience (SD) & $16(9)$ & $14(7)$ \\
\hline Mean years of conference interpreting experience (SD) & $13(9)$ & $9(7)$ \\
\hline Percentage of interpreting from English into Auslan & $63 \%$ & $60 \%$ \\
\hline Percentage of interpreting from Auslan into English & $37 \%$ & $40 \%$ \\
\hline Interpreters with no directionality preference (\%) & $11(79 \%)$ & $9(53 \%)$ \\
\hline Interpreters preferring English-to-Auslan interpreting (\%) & $2(14 \%)$ & $4(24 \%)$ \\
\hline Interpreters preferring Auslan-to-English interpreting (\%) & 0 & $4(24 \%)$ \\
\hline Interpreters uncertain about directionality preference (\%) & $1(7 \%)$ & 0 \\
\hline
\end{tabular}

Note. Interpreting experience means the years of working as a paid interpreter, irrespective of NAATI accreditation.

\subsection{Materials}

The main goals in creating the English and Auslan source texts were achieving comparability (of context, topic, presentation rate, and length) and authenticity. Both texts were created for a notional national conference themed "Interpreting and Human Rights" . To make the texts as realistic as possible, each presenter was briefed in terms of the conference theme and the intended audience of their presentation. The audience for both presentations was described as including English-speaking attendees who did not understand Auslan, and deaf professionals who were bilingual in both Auslan and written English. It was assumed that the audience was familiar with human rights issues. Each presenter created their own presentation based on their professional expertise, rather than actors being given a speech to read out, thus increasing authenticity and content validity.

For the English source text, a solicitor (a native Australian English speaker based in Sydney) was filmed giving a presentation entitled "Interpreting and Human Rights." He was filmed giving his presentation, using printed PowerPoint slides as a prompt. The manager of a Deaf Community service organization (a deaf native Auslan signer based in Sydney) provided the Auslan source text, giving a signed presentation. The topic was "Deaf People and Human Rights," reporting findings from an international research project. The deaf presenter was also filmed giving his presentation based on PowerPoint slides. 
Each presenter started with a brief introduction (about three minutes), paused for a few seconds, and then gave their formal presentation (approximately $17 \mathrm{~min}$ utes). The researcher served as each presenter's audience and filmed each presentation as an mp4 video, using an Ultra HD Flip camera. A native Auslan signer was also present as an audience member for the filming of the Auslan presentation. Due to environmental constraints, the camera captured the presenters but did not capture their PowerPoint slides.

\subsection{Procedure}

In order to replicate a real conference interpreting experience and encourage pre-task preparation, the following materials were sent to participants two weeks prior to data collection: task instructions (for example, conference theme, description of the intended audience, each presenter's name and background, presentation title), glossary (legal terms in the English source text, fingerspelled words in the Auslan source text), and copies of PowerPoint slides for both presentations.

Participants were tested individually, predominantly in Deaf Community service organizations ${ }^{9}$ in their respective cities between March and July 2011. After completing a consent form and a demographic questionnaire, each participant was filmed simultaneously interpreting the source text videos shown on a laptop computer; first, the English source text, then the Auslan source text. Each participant watched the first three minutes of each video to warm up and then simultaneously interpreted the remaining 17 minutes of formal presentation. During each task, the researcher sat next to the camera as the participant's audience, coordinating the filming. After each interpretation, the researcher engaged the participant in a short semi-structured interview. Participation took approximately one and a half hours in total.

\subsection{Analytic assessment of simultaneous interpreting performance}

Two external raters were selected to assess participants' simultaneous interpreting performances using pre-designed rubrics. For the purpose of this paper, they have been named as Morgan and Jamie. Each rater met the following criteria: native English speaker, hearing native signer, and NAATI-accredited professional level Auslan/English interpreter with considerable interpreting experience. In terms of assessment experience, both Morgan and Jamie were full-time signed language interpreter educators in an academic interpreter education program. They were also experienced assessors for national NAATI accreditation exams.

Two rubrics were developed for assessing participants' simultaneous interpreting performances, one rubric for one language direction. Each rubric comprised the following four macro-level assessment criteria:

- accuracy (a maximum score of 50), consisting of the following five sub-criteria: minimal unjustifiable additions, minimal unjustifiable omissions, minimal unjustifiable substitutions, minimal unjustifiable intrusions, and cohesion and coherence;

- target text features (a maximum score of 20), including the following three subcriteria: grammaticality, appropriate vocabulary, and conveying speaker/signer register and affect;

- delivery features (a maximum score of 15), consisting of the following three subcriteria: clarity of articulation, fluency, and natural prosody; 
- processing skills (a maximum score of 15), comprising the following five sub-criteria: use of time lag, a free-literal interpretation continuum with appropriate shifts in between, strategic additions, strategic omissions, and successful anticipations.

A sub-score was assigned to each macro-level assessment criterion according to the following five levels:

- poor (less than 50\%);

- average (50\%-64\%);

$-\operatorname{good}(65 \%-74 \%)$

- very good (75\%-84\%);

- excellent (85\%-100\%).

Four sub-scores were then summed up to form the total score for a participant, with the maximum total score being 100. For example, in relation to English-toAuslan simultaneous interpreting performance, if a participant received a score of 43 for accuracy $(86 \%$, in the excellent range), 15 for target text features $(75 \%$, in the very good range), 11.25 for delivery features ( $75 \%$, in the very good range), and 11.25 for processing skills (75\%, in the very good range), the participant's total score for this language direction was 80.50 .

Morgan assessed all 31 participants' simultaneous interpreting performances in both language directions. For inter-rater reliability purposes, Jamie evaluated 16 randomly chosen participants' simultaneous interpreting performances in both language directions. Pearson correlation coefficients were used as inter-rater reliability estimates. Regarding English-to-Auslan simultaneous interpreting performance, interrater reliability was $r=.87, N=16, p<.001$. With respect to Auslan-to-English simultaneous interpreting performance, inter-rater reliability was $r=.92, N=16$, $p<.001$. Given that the absolute minimum of acceptable inter-rater reliability is .7 (McNamara 2000), both inter-rater reliability estimates of this study were considered satisfactory. Quantitative results based on Morgan's ratings are reported below.

\section{Quantitative results}

A mixed between-within subjects analysis of variance (ANOVA) was conducted to examine the impact of directionality (English-to-Auslan, Auslan-to-English) and age of signed language acquisition (native signer, non-native signer) on all participants' simultaneous interpreting performance (that is, the total score). The main effect for directionality was not significant, Wilks' Lambda $=.98, F(1,29)=.73, p=.40$. In other words, all 31 professional interpreters' English-to-Auslan simultaneous interpreting performance was similar to their Auslan-to-English simultaneous interpreting performance in terms of the total score. There was no significant main effect for age of signed language acquisition, $F(1,29)=.88, p=.36$. That is, the native signers were similar to the non-native signers in overall simultaneous interpreting performance (collapsing English-to-Auslan and Auslan-to-English simultaneous interpreting performances). Finally, there was no significant interaction between directionality and age of signed language acquisition, Wilks' Lambda $=.91, F(1,29)=2.74, p=.11$. 


\subsection{Directionality effects on simultaneous interpreting performance}

Apart from the above main analysis, paired-samples $t$-tests were used to compare each group's English-to-Auslan simultaneous interpreting performance with their Auslan-to-English simultaneous interpreting performance. As shown in Table 2, there was no significant difference between the native signers' English-to-Auslan simultaneous interpreting performance and their Auslan-to-English simultaneous interpreting performance in terms of the total score, $t(13)=.60, p=.56$. Regarding sub-scores, there were no significant differences between the native signers' Englishto-Auslan simultaneous interpreting performance and their Auslan-to-English simultaneous interpreting performance in terms of accuracy, target text features, delivery features, or processing skills, with all $p$ values larger than .05.

TABLE 2

Native signers' English-to-Auslan simultaneous interpreting performance versus their Auslan-to-English simultaneous interpreting performance

\begin{tabular}{|l|c|c|c|c|c|c|}
\hline \multirow{2}{*}{ Analytic assessment } & English-to-Auslan & Auslan-to-English & \multirow{2}{*}{$t$} & $d f$ & \multirow{2}{*}{$p$} & \multirow{2}{*}{$\eta^{2}$} \\
\cline { 2 - 6 } & Mean (SD) & Mean (SD) & & & \\
\hline Total score & $75.86(15.05)$ & $74.03(17.09)$ & .60 & 13 & .56 & - \\
\hline Accuracy & $37.86(8.54)$ & $37.39(8.88)$ & .32 & 13 & .75 & - \\
\hline Target text features & $15.43(2.77)$ & $14.84(3.24)$ & .85 & 13 & .41 & - \\
\hline Delivery features & $11.70(2.19)$ & $11.01(2.52)$ & .98 & 13 & .35 & - \\
\hline Processing skills & $10.88(2.35)$ & $10.79(2.66)$ & .20 & 13 & .84 & - \\
\hline
\end{tabular}

Note. All $p$ values were two-tailed. Effect size $\eta^{2}$ was calculated when there was a significant difference.

As shown in Table 3 below, in terms of the total score, there was no significant difference between the non-native signers' English-to-Auslan simultaneous interpreting performance and their Auslan-to-English simultaneous interpreting performance, $t(16)=-1.74, p=.10$. However, there was a substantial directionality effect on target text features: the non-native signers' English-to-Auslan (L1-to-L2) simultaneous interpreting performance was significantly inferior to their Auslan-to-English (L2-to-L1) simultaneous interpreting performance in terms of target text features, $t(16)=-3.16, p=.006, \eta^{2}=.38$. There were no significant differences between the non-native signers' English-to-Auslan simultaneous interpreting performance and their Auslan-to-English simultaneous interpreting performance in terms of accuracy, delivery features, or processing skills, with $p$ values above .05 .

TABLE 3

Non-native signers' English-to-Auslan simultaneous interpreting performance versus their Auslan-to-English simultaneous interpreting performance

\begin{tabular}{|l|c|c|c|c|c|c|}
\hline \multirow{2}{*}{ Analytic assessment } & English-to-Auslan & Auslan-to-English & \multirow{2}{*}{$t$} & \multirow{2}{*}{$d f$} & \multirow{2}{*}{$p$} & \multirow{2}{*}{$\eta^{2}$} \\
\cline { 2 - 6 } & Mean (SD) & Mean (SD) & & & & \\
\hline Total score & $67.52(11.32)$ & $73.29(15.68)$ & -1.74 & 16 & .10 & - \\
\hline Accuracy & $33.79(6.28)$ & $36.24(8.39)$ & -1.21 & 16 & .24 & - \\
\hline Target text features & $13.49(2.24)$ & $15.00(2.89)$ & -3.16 & 16 & .006 & .38 \\
\hline Delivery features & $10.03(1.90)$ & $11.20(2.54)$ & -1.97 & 16 & .07 & - \\
\hline Processing skills & $10.21(1.85)$ & $10.85(2.45)$ & -1.37 & 16 & .19 & - \\
\hline
\end{tabular}

Note. All $p$ values were two-tailed. Bold type indicated $p<.05$. Effect size $\eta^{2}$ was calculated when there was a significant difference. 


\subsection{Native signers versus non-native signers}

Independent-samples $t$-tests were conducted to compare the native signers with the non-native signers in terms of simultaneous interpreting performance in each language direction. As can be seen in Table 4 below, the native signers were similar to the non-native signers in the total score of English-to-Auslan simultaneous interpreting performance, $t(29)=1.76, p=.09$. Nonetheless, the two groups differed substantially in two sub-scores: the native signers were significantly superior to the non-native signers in terms of both the target text features and the delivery features of English-to-Auslan simultaneous interpreting performance, $p=.039$ and $p=.03$, respectively. However, the native signers were similar to the non-native signers in terms of the accuracy and processing skills of English-to-Auslan simultaneous interpreting performance, with both $p$ values above .05 .

TABLE 4

Native signers versus non-native signers in terms of English-to-Auslan simultaneous interpreting performance

\begin{tabular}{|c|c|c|c|c|c|c|}
\hline \multirow[t]{2}{*}{ Analytic assessment } & $\begin{array}{l}\text { Native signers } \\
\quad(\mathrm{N}=14)\end{array}$ & $\begin{array}{l}\text { Non-native signers } \\
\qquad(\mathrm{N}=17)\end{array}$ & \multirow[t]{2}{*}{$t$} & \multirow[t]{2}{*}{$d f$} & \multirow[t]{2}{*}{$p$} & \multirow[t]{2}{*}{$\eta^{2}$} \\
\hline & Mean $(S D)$ & Mean $(S D)$ & & & & \\
\hline Total score & $75.86(15.05)$ & $67.52(11.32)$ & 1.76 & 29 & .09 & - \\
\hline Accuracy & $37.86(8.54)$ & $33.79(6.28)$ & 1.53 & 29 & .14 & - \\
\hline Target text features & $15.43(2.77)$ & $13.49(2.24)$ & 2.16 & 29 & .039 & .14 \\
\hline Delivery features & $11.70(2.19)$ & $10.03(1.90)$ & 2.28 & 29 & .03 & .15 \\
\hline Processing skills & $10.88(2.35)$ & $10.21(1.85)$ & .89 & 29 & .38 & - \\
\hline
\end{tabular}

Note. All $p$ values were two-tailed. Bold type indicated $p<.05$. Effect size $\eta^{2}$ was calculated when there was a significant difference.

As shown in Table 5, the native signers were comparable to the non-native signers in the total score of Auslan-to-English simultaneous interpreting performance, $t(29)=.13, p=.90$. Additionally, the two groups were similar in terms of the accuracy, target text features, delivery features, and processing skills of Auslan-to-English simultaneous interpreting performance, with all $p$ values larger than .05 .

TABLE 5

Native signers versus non-native signers in terms of Auslan-to-English simultaneous interpreting performance

\begin{tabular}{|c|c|c|c|c|c|c|}
\hline \multirow[t]{2}{*}{ Analytic assessment } & $\begin{array}{l}\text { Native signers } \\
\qquad(\mathrm{N}=14)\end{array}$ & $\begin{array}{c}\text { Non-native signers } \\
(\mathrm{N}=17)\end{array}$ & \multirow[t]{2}{*}{$t$} & \multirow[t]{2}{*}{$d f$} & \multirow{2}{*}{$p$} & \multirow[t]{2}{*}{$\eta^{2}$} \\
\hline & Mean $(S D)$ & Mean $(S D)$ & & & & \\
\hline Total score & 74.03 (17.09) & $73.29(15.68)$ & .13 & 29 & .90 & - \\
\hline Accuracy & $37.39(8.88)$ & $36.24(8.39)$ & .37 & 29 & .71 & - \\
\hline Target text features & $14.84(3.24)$ & $15.00(2.89)$ & -.14 & 29 & .89 & - \\
\hline Delivery features & $11.01(2.52)$ & $11.20(2.54)$ & -.21 & 29 & .83 & - \\
\hline Processing skills & $10.79(2.66)$ & $10.85(2.45)$ & -.07 & 29 & .94 & - \\
\hline
\end{tabular}

Note. All $p$ values were two-tailed. Effect size $\eta^{2}$ was calculated when there was a significant difference. 


\subsection{Results of correlational analysis}

A significant, moderate, positive correlation was identified between all 31 professional interpreters' English-to-Auslan simultaneous interpreting performance (the total score) and their Auslan-to-English simultaneous interpreting performance (the total score), $r=.62, N=31, p<.001, r^{2}=.38$. There was also a significant, moderate, positive correlation between the native signers' English-to-Auslan simultaneous interpreting performance and their Auslan-to-English simultaneous interpreting performance, $r=.75, N=14, p=.002, r^{2}=.56$. Finally, there was a significant, moderate, positive correlation between the non-native signers' English-to-Auslan simultaneous interpreting performance and their Auslan-to-English simultaneous interpreting performance, $r=.53, N=17, p=.03, r^{2}=.28$. These findings are consistent with van Dijk, Boers et al.'s (2011) results that there was a significant, moderate, positive correlation between experienced SLN/Dutch interpreters' Dutchto-SLN simultaneous interpreting performance and their SLN-to-Dutch simultaneous interpreting performance. The findings suggest that in the present study both simultaneous interpreting tasks tapped into similar cognitive resources and required similar interpreting skills.

In order to replicate Nicodemus's (2011) empirical study noted earlier, we repeated all the above statistical analyses on participants who had over 10 years of interpreting experience. These participants comprised 11 native signers $(9$ female and 2 male; mean age $44, S D=12$; with an average of 20 years of interpreting experience, $S D=5$ ) and 11 non-native signers (10 female and 1 male; mean age $45, S D=9$; with an average of 18 years of interpreting experience, $S D=6$ ). The result pattern remained the same, apart from the change that there were no significant differences between the native signers and the non-native signers in the target text features or delivery features of English-to-Auslan simultaneous interpreting performance. This finding suggests that native signers are comparable to non-native signers in simultaneous interpreting performance, as long as both groups are highly experienced interpreters. The quantitative results will be discussed in a later section.

\section{Qualitative results}

While the quantitative results reveal no significant directionality effect on the simultaneous interpreting performance of all 31 participants, an analysis of the qualitative interview data in this section shows that many participants perceived more difficulties in simultaneous interpreting from Auslan into English than vice versa. Interview data from all participants were fully transcribed, and analyzed for recurring themes through open coding in NVivo ${ }^{10}$. Each participant was assigned a pseudonym (see Appendix) in the interest of maintaining confidentiality. 
TABLE 6

Professional interpreters' perceived difficulties in each simultaneous interpreting task

\begin{tabular}{|c|c|}
\hline $\begin{array}{l}\text { English-to-Auslan simultaneous interpreting } \\
\text { (N = number of participants) }\end{array}$ & $\begin{array}{l}\text { Auslan-to-English simultaneous interpreting } \\
\text { ( } \mathrm{N}=\text { number of participants) }\end{array}$ \\
\hline $\begin{array}{l}\text { Difficulties in the English source text: } \\
\text { - Legal terms }(\mathrm{N}=13) \\
\text { - Dense information }(\mathrm{N}=6) \\
\text { - The hearing presenter's pace was fast }(\mathrm{N}=8)\end{array}$ & $\begin{array}{l}\text { Difficulties in the Auslan source text: } \\
\text { - The deaf presenter's use of International Signs } \\
\text { and/or other particular signs }(\mathrm{N}=22) \\
\text { - Unfamiliarity with the deaf presenter }(\mathrm{N}=16) \\
\text { - Unfamiliarity with the deaf presenter's signing } \\
\text { style }(\mathrm{N}=14) \\
\text { - Unclear bits of information, unclear aim of the } \\
\text { presentation, unclear logic thread }(\mathrm{N}=12) \\
\text { - Unfamiliarity with the subject matter }(\mathrm{N}=9) \\
\text { - Numbers }(\mathrm{N}=15)\end{array}$ \\
\hline $\begin{array}{l}\text { Difficulties due to the research setting: } \\
\text { - No real deaf audience and interpreting to a } \\
\text { camera }(N=15) \\
\text { - No team interpreter }(\mathrm{N}=9) \\
\text { - No PowerPoint slides on show }(\mathrm{N}=3)\end{array}$ & $\begin{array}{l}\text { Difficulties due to the research setting: } \\
\text { - A two-dimensional video rather than a real } \\
\text { deaf person presenting }(\mathrm{N}=9) \\
\text { - No chance to meet the deaf presenter } \\
\text { beforehand }(\mathrm{N}=11) \\
\text { - No team interpreter }(\mathrm{N}=15) \\
\text { - No PowerPoint slides on show }(\mathrm{N}=13)\end{array}$ \\
\hline
\end{tabular}

Note. There were no clear differences in the number of responses from native signers and non-native signers.

As shown in Table 6, participants reported more difficulties in the Auslan source text than in the English one. Regarding the English source text, 13 participants pointed out that legal terms constituted the most prominent difficulty, such as "unjustifiable hardship," "reasonable adjustment," "Anti-Discrimination Act," and "United Nations Convention on the Rights of Persons with Disabilities." Some participants employed linguistic coping strategies (for example, fingerspelling, abbreviation, placement) to interpret the legal terms.

In relation to the Auslan source text, the majority of participants reported that they had encountered Auslan comprehension problems due to the deaf presenter's use of International Signs ${ }^{11}$ and/or other particular signs, unfamiliarity with him and his signing style, vagueness in the Auslan source text, and unfamiliarity with the subject matter. This is evidenced by native signer Shannon's (based in Melbourne) comments below:

I think he [the deaf presenter based in Sydney] has an idiosyncratic signing style. I believe that if he was presenting at conferences or workshops in Australia, that he would generally use interpreters who are familiar with him. And that's something I would certainly advocate, because he has a particular style. ... Because he has worked overseas, $\underline{\text { I believe that he has a lot of International Sign influence in his signs. ... He uses sort }}$ of English word order in some of his signs, although generally he is still quite Auslan in his signing. ... Location, we need to have regular contact with a deaf signer before we can feel confident to do an effective job.

In addition, 16 participants (such as native signer Shannon noted above) reported that they were not familiar with the deaf presenter, either because they lived in different cities from him or because they had not worked with him before. An analysis of the qualitative interview data indicates that a number of participants' familiarity with the deaf presenter rendered it easy for them to comprehend his Auslan source text, thus helping them perform an effective job. Nevertheless, participants' familiarity with 
the hearing presenter did not seem to be important for interpreting from English into Auslan.

As can also be seen in Table 6 above, the artificial testing environment in this study made it more difficult to interpret the Auslan source text than the English one. In this respect, the most prominent difficulty in the English-to-Auslan simultaneous interpreting task was the absence of real deaf audience (a limitation of this study). In relation to the research setting, participants reported the following four main difficulties in the Auslan-to-English simultaneous interpreting task: a two-dimensional video instead of a real deaf person presenting, no chance to meet the deaf presenter beforehand, no team interpreter, and no visual aids. This is partly supported by nonnative signer Sabrina's comments as follows:

It's interesting, because you [the researcher] asked me what was the most difficult thing when I was interpreting from English into Auslan, and the most difficult thing for me was not having feedback from the deaf people in the audience [because deaf audience members were not provided in this research setting]. When interpreting the Auslan presentation into English, the most difficult thing was that I didn't have contact with the deaf presenter. I couldn't tell him to hold, or, just shoot him a sign that says "77 did that, or 77 didn't do that, which one is it?" Just those little clarifications make so much of a difference. I wish he could just give me a look as "Yes" or "No." ... I think I had comprehension problems with the Auslan presentation. ... He is a very clear signer, and his speed is really not an issue, it's just about all those numbers. It would have been a lot easier if I could see the PowerPoint slides on the screen. ... I was thinking, "I wish I had someone prompting me." And I think I rely on a team interpreter much more when I interpret from Auslan into English than the other way around.

Both the quantitative and qualitative results are discussed below in relation to previous studies.

\section{Discussion}

It is important to note that the quantitative results from this study may have been confounded by the following factors: the relatively small sample size, participants' degree of familiarity with the topics of the source texts, their degree of familiarity with the presenters, the amount of pre-task preparation, their educational background, level of interpreter education, years of interpreting experience, conference interpreting experience, working as full-time or part-time interpreters, participation in professional development activities, critical self-reflection on interpreting practice, and involvement in the Australian Deaf Community. Regarding the sample size, it should also be acknowledged that, given the population of signed language interpreters in Australia ${ }^{12}$, it would not have been possible to recruit more participants for this study. In fact, the sample size of the present study is still one of the largest in comparison with other empirical research into actual signed language interpreting performance (see section 2.2).

\subsection{Directionality effects on simultaneous interpreting performance}

Results reveal that all 31 professional interpreters' English-to-Auslan simultaneous interpreting performance was similar to their Auslan-to-English simultaneous interpreting performance in terms of the total score. This finding suggests that there was 
no significant directionality effect on the professional interpreters' simultaneous interpreting performance. The result is encouraging for signed language interpreting students and practitioners, because anecdotally many of them are not confident about their abilities to interpret from a signed language into a spoken language. This finding may be attributable to an offset between ineffective self-monitoring of Auslan output in English-to-Auslan simultaneous interpreting and difficulties in comprehending Auslan input in Auslan-to-English simultaneous interpreting, discussed as follows.

When working from a spoken language into a signed language, signed language interpreters cannot see their own facial expression or mouthing; they view their hands in the lower visual field (or their hands may also fall out of their eyesight); and they do not look directly at their hands while signing. This means that signed language interpreters cannot actively monitor their signed output for comprehensibility or grammaticality. Visual feedback may be less effective than auditory feedback in online error detection (Nicodemus and Emmorey 2013). Hence, signed language interpreters often rely on deaf clients' feedback (in the form of the deaf clients' facial expression, head nodding, etc.) to gauge whether their interpretations are comprehensible and whether they need to make adjustments. Given that there was no real deaf audience in the English-to-Auslan simultaneous interpreting task in the current study, participants could not have their Auslan output monitored effectively. When working from Auslan into English, on the other hand, participants could immediately monitor their English lexical choices, grammar, coherence, register, pace, and prosody, as they could immediately hear their own interpretations. However, the majority of participants encountered Auslan comprehension problems largely due to unfamiliarity with the deaf presenter and the constraints of the research setting (see the qualitative results in Table 6). Hence, a lack of self-monitoring of the Auslan output and difficulty in comprehending the Auslan input may have resulted in no significant directionality effect on all 31 participants' simultaneous interpreting performance.

As expected, results reveal that the native signers' English-to-Auslan simultaneous interpreting performance was as good as their Auslan-to-English simultaneous interpreting performance in terms of the total score and sub-scores. This finding indicates that there was no significant directionality effect on the native signers' simultaneous interpreting performance. This outcome conflicts with van Dijk, Boers et al.'s (2011) results that native signers' Dutch-to-SLN simultaneous interpreting performance was significantly better than their SLN-to-Dutch simultaneous interpreting performance. The discrepant findings may be due to methodological differences between the two studies (for example, type of source text, method for assessing simultaneous interpreting performance). Interestingly, the finding in the present study echoes the prior results obtained by Chang and Schallert (2007), who found no significant directionality effect on the simultaneous interpreting performance of professional interpreters with equal proficiency in English and Mandarin. Our finding also lends some credence to the claim that balanced bilingual interpreters are free from the rule of directionality because they work between two native languages (see Denissenko 1989; Seleskovitch 1978).

In addition, results show that the non-native signers' English-to-Auslan (L1-to-L2) simultaneous interpreting performance was similar to their Auslan-to- 
English (L2-to-L1) simultaneous interpreting performance in terms of the total score. This finding indicates that there was no significant directionality effect on the nonnative signers' simultaneous interpreting performance. Again, this contradicts the results obtained by van Dijk, Boers et al. (2011), who found that non-native signers' Dutch-to-SLN (L1-to-L2) simultaneous interpreting performance was significantly superior to their SLN-to-Dutch (L2-to-L1) simultaneous interpreting performance. Nevertheless, our finding is in accordance with Nicodemus's (2011) results that there was no significant directionality effect on the simultaneous interpreting performance of experienced ASL/English interpreters (non-native signers). Our finding is also in line with the results of Tommola and Helevä (1998) and Tommola and Laakso (1997), who found no significant directionality effect on the simultaneous interpreting performance of student interpreters. A number of factors may explain our finding. To begin with, given that the majority of the non-native signers in the present study had over 10 years of interpreting experience, they may have developed relatively equal proficiency in English and Auslan as well as relatively balanced competence of interpreting in each language direction. Alternatively, compared with other variables (for example, interpreters' interpreting skills and interpreting experience), directionality may have less impact on simultaneous interpreting performance (see Gile 2005; Kalina 2005; Pavlović 2007; Seel 2005).

Interestingly, the non-native signers' English-to-Auslan (L1-to-L2) simultaneous interpreting performance was significantly inferior to their Aulsan-to-English (L2-to-L1) simultaneous interpreting performance in terms of target text features. This corroborates the results of Chang and Schallert (2007), who found that professional Mandarin/English interpreters made significantly more target-language-use errors when simultaneously interpreting from L1 (Mandarin) into L2 (English) than vice versa. The finding highlights the importance for non-native signer interpreters to continue to improve their signed language (L2) proficiency (see Taylor 1993; 2002 for a similar claim). This result supports Donovan's (2005) view that both student interpreters and professional interpreters should make constant efforts to refine their non-native language skills.

\subsection{Native signers versus non-native signers}

Further, as in van Dijk, Boers et al.'s (2011) study, the present study found that the native signers were similar to the non-native signers in overall simultaneous interpreting performance (collapsing English-to-Auslan and Auslan-to-English simultaneous interpreting performances). Another revealing finding is that the native signers were similar to the non-native signers in the total score of English-to-Auslan simultaneous interpreting performance. This new finding suggests that there was no significant age of signed language acquisition effect on the professional interpreters' English-to-Auslan simultaneous interpreting performance. The finding indicates that signed language nativeness may not be crucial for determining the simultaneous interpreting performance of professional signed language interpreters.

As expected, the native signers were significantly superior to the non-native signers in terms of the target text features and delivery features of English-to-Auslan simultaneous interpreting performance. These findings are consistent with Napier's (2006) results that a native signer interpreter's Auslan target text was more idiomatic 
and natural than that of a non-native signer interpreter. The findings also support Nicodemus and Emmorey's (2013) results that native signer interpreters' self-perceived proficiency in a signed language (ASL) was substantially higher than that of non-native signer interpreters. Again, these findings highlight the need for non-native signer interpreters to further develop their signed language (L2) skills. Regarding differences between native signers and non-native signers, native signer Rachael commented:

I believe that there is a big difference between native signers and non-native signers when they interpret from English into Auslan. I truly believe that. I am often told that I use a lot of space and many non-native signers do not exploit space as much (space is used for linguistic purposes in signed languages). I also use a lot of facial expression and sometimes that is not so obvious in non-native signers (facial expression has important functions in signed languages, such as to mark questions and to show emotional state).

\section{Similarly, native signer Lauren commented:}

I think it is just more natural for native signers to use more space in English-to-Auslan interpreting. Spreading it out gives you a little bit more flexibility. ... Once I have put the information into Auslan in my head, it just comes out on my hands naturally. So, while that is happening, I can still be listening. I don't necessarily have to concentrate on making sure my hands are in the right areas. That sort of just happens.

Participants in this study exhibited marked variability in Auslan proficiency. In the English-to-Auslan simultaneous interpretation data, several non-native signer interpreters showed inappropriate signing style and use of Auslan (for example, exaggerated facial expression, unclear production of signs, inappropriate prosody). By contrast, many other non-native signer interpreters demonstrated near-native proficiency in Auslan, in that their Auslan output was fluent, smooth, and clear.

Moreover, this study found that the native signers were similar to the non-native signers in terms of the total score and sub-scores of Auslan-to-English simultaneous interpreting performance. These findings suggest that there was no significant age of signed language acquisition effect on the professional interpreters' Auslan-to-English simultaneous interpreting performance. There are some possible explanations for the results. First, both the native signers and the non-native signers encountered some Auslan comprehension problems when interpreting the Auslan source text into English, partly due to unfamiliarity with the deaf presenter, no opportunity to meet him beforehand, and no PowerPoint slides on show. Second, Auslan-to-English interpreting performance may be more related to an interpreter's educational background, English vocabulary bank, and interpreting experience than to Auslan nativeness. These assumptions merit further research.

\subsection{Familiarity with the deaf presenter}

There is a considerable degree of signed language variation in the Deaf Community of a country (Napier, McKee et al. 2006/2010; Nicodemus and Emmorey 2013; Schembri, Johnston et al. 2006; Schembri, McKee et al. 2009). In other words, deaf Auslan signers often differ from one another in terms of signing style and lexical choice. An analysis of the qualitative interview data reveals that many interpreters 
in the present study encountered Auslan comprehension problems due to unfamiliarity with the deaf presenter. Several interpreters who were familiar with the deaf presenter in real life produced highly accurate Auslan-to-English interpretations in this study. These findings support the paradigm that deaf professionals should work with designated interpreters (see Hauser, Finch et al. 2008). Even highly skilled interpreters find it difficult to interpret for deaf professionals with whom they have never worked before (Hurwitz 2008). Familiarity, regular contact, mutual trust, rapport, and teamwork between a deaf professional and a designated interpreter, contribute to the interpreter's optimal interpreting performance (Hauser and Hauser 2008). Napier, Carmichael et al. (2008) found that in a monologic seminar presentation a deaf presenter and two designated interpreters strategically used pauses, nods, and eye contact as contextualization cues in order to signal comprehension, mark episodes, and control the pace of the presentation. Therefore, if the professional interpreters in the current study had been in the room with the deaf presenter and had met him beforehand, they would have been able to negotiate, agree on, and implement similar strategies. Similarly, Gile (1995/2009) maintains that interpreters' good knowledge of the speaker and subject matter often enables them to anticipate information in the source text.

This study has some limitations that need to be acknowledged. To begin with, given the relatively small sample size and considerable variability in participants' demographic characteristics, findings of the study may not be generalized to the broader community of signed language interpreters. Further research should include larger samples of professional signed language interpreters who are relatively homogenous in demographic data (for example, educational background, level of interpreter education, interpreting experience). Secondly, the researcher's presence as participants' audience in both interpreting tasks, the researcher's linguistic background (a native speaker of Mandarin with near-native proficiency in English and intermediate proficiency in Auslan), and the lack of real conference audience may have affected the participants' simultaneous interpreting performances in this study. Thirdly, the research setting in this study prevented participants from using the following coping strategies that are available in real-life conference interpreting assignments:

- meeting the hearing and deaf presenters beforehand to clarify issues and to familiarize with their pace and style;

- receiving feedback from the audience;

- referring to visual aids (e.g., PowerPoint slides);

- working with a team interpreter.

Therefore, participants' simultaneous interpreting performances in this artificial testing situation may not represent their optimal interpreting competence in realtime assignments. Fourthly, as signed language interpreters in Australia do not work full-time as conference interpreters due to a lack of job availability, the majority of participants work primarily in community settings in real life. This means that some participants' interpreting performance in the present study may not represent their optimal interpreting performance in community settings. 


\section{Conclusion}

This study has investigated the effects of directionality and age of signed language acquisition on the simultaneous interpreting performance of professional Auslan/ English interpreters, who consisted of native signers and non-native signers. Results show no significant differences between the native signers' English-to-Auslan simultaneous interpreting performance and their Auslan-to-English simultaneous interpreting performance, suggesting that balanced bilingual interpreters are free from the rule of directionality. Although this finding held true for the non-native signers, results indicate a need from them to further enhance their signed language (L2) skills. Furthermore, although the native signers were similar to the non-native signers in overall simultaneous interpreting performance in each language direction, the native signers were significantly better than the non-native signers in both the target text features and delivery features of English-to-Auslan simultaneous interpreting performance. These findings also suggest that the non-native signers need to further improve their signed language (L2) proficiency. Interestingly, although the quantitative results show no significant directionality effect on all participants' simultaneous interpreting performance, an analysis of the qualitative interview data reveals that many participants encountered more difficulties when interpreting from Auslan into English than vice versa.

The findings discussed here have implications for the interpreting profession and interpreter education. The results support the paradigm that deaf professionals work with designated interpreters, or at least work with interpreters who have regular contact with them, in order to develop familiarity and mutual trust. It is also important for interpreters to prepare for interpreting assignments in order to familiarize themselves with speakers and subject matter. The findings also highlight the need for signed language interpreters to film their interpretations in both language directions as a means for conducting critical self-analysis and increasing self-awareness. Professional development workshops can guide interpreting practitioners in how to conduct critical self-analysis. The interpreting profession can encourage native and non-native signer interpreters to work together and learn from each other. Interpreter education programs may consider hiring more deaf native signers as instructors or tutors to enhance the signed language proficiency of student interpreters, and to provide constructive feedback on the students' interpreting performance from a spoken language into a signed language.

The current study touches upon some questions in need of further investigation. Future research may replicate this study on larger samples of spoken and signed language interpreters, so as to offer more insight into directionality effects on actual interpreting performance. It would be worthwhile comparing expert interpreters with novice interpreters in terms of their simultaneous interpreting performance in both language directions, to investigate the effects of expertise and directionality on simultaneous interpreting performance. It would also be of interest to analyze authentic conference level signed language interpretation data. 


\section{ACKNOWLEDGMENTS}

This article presents selected findings from Jihong Wang's PhD thesis ("Working Memory and Signed Language Interpreting") submitted to Macquarie University in 2013. This research was supported by Research Enhancement Fund HDR in the Department of Linguistics, Macquarie University. We thank all professional Auslan/English interpreters for their participation in this study. We are truly grateful to Della Goswell for conducting inter-rater reliability checks for the assessment of simultaneous interpreting performances. We would also like to thank Georgina Major and the anonymous peer reviewers for their valuable comments on earlier drafts of this paper.

\section{NOTES}

1. Here the term native language (L1) means the language that a person acquired from birth and which is often considered as their strongest language. The term non-native language (L2) refers to a language that a person acquired or learned later in life but which is not as strong as the L1.

2. Spoken language conference interpreters typically work in simultaneous mode in soundproof booths with headsets and microphones at the back of a conference venue - a practice initiated at the Nuremberg War Crime Trials between 1945 and 1946 (Gaiba 1999).

3. While five interpreters had English as their L1 and French as their L2, the remaining 11 interpreters had French as their L1 and English as their L2.

4. Johnston and Schembri (2007: 34) define fingerspelling as "the use of hand configurations to represent the letters of a writing system." In relation to fingerspelling, deaf Auslan signers use a twohanded alphabet to spell selected words out manually, letter by letter. English words are frequently borrowed when there are no Auslan lexical equivalents, and so need to be spelled on the fingers.

5. Goswell (2011: 61) defines role shift as "a mimetic feature, whereby the signer depicts the affect, speech and/or action of another character, including themselves in a past or future time."

6. In Australia, all signed language interpreters, spoken language interpreters, and translators are accredited through NAATI. Two accreditation levels are available for Auslan/English interpreters - Paraprofessional Interpreter and Professional Interpreter. Paraprofessional Interpreters typically undertake the interpretation of non-specialist dialogues. Professional Interpreter is the minimum level recommended by NAATI for professional interpreting work in most semi-specialized settings, such as banking, law, health, and social and community services. For further detail, see "Outlines of NAATI Credentials" (2010) at http://www.naati.com.au/pdf/misc/Outliness\%20of\%20NAATI\% 20Credentials.pdf.

7. It is important to note that not all hearing children with deaf parents may necessarily be native signers.

8. The theme was inspired by a session entitled "Translation and Interpreting as a Human Right" at the "Emerging Topics in Translation and Interpreting international/Nuovi percorsi in traduzione e interpretazione" international conference at Università degli Studi di Trieste, Trieste, 16-18 June 2010. See http://www.dslit.units.it/images/page35/programma\%2014\%20giugno_2.pdf.

9. Only one participant was tested at home, due to her limited availability.

10. NVivo software can be used to analyze interview data in qualitative research and mixed methods research. NVivo: Visited on 16 October 2013, <http://www.qsrinternational.com/products_nvivo. aspx>.

11. Johnston and Schembri (2007: 73) define International Sign Language as "a form of signed language using a special lexicon devised to assist communication between deaf people who had no language in common (either signed or written)."

12. Between November 1982 when testing started and October 2012, 932 Auslan/English interpreters were accredited by NAATI. Of these, 772 (83\%) were accredited at the Paraprofessional Interpreter level, and 160 (17\%) at the Professional Interpreter level. Foote, Robert (3 October 2012): personal communication, Sydney.

\section{REFERENCES}

Al-Salman, Saleh and Al-Khanji, Raja (2002): The Native Language Factor in Simultaneous Interpretation in an Arabic/English Context. Meta. 47(4):607-626.

BARTŁOMIEJCZyK, Magdalena (2004): Simultaneous Interpreting A-B vs. B-A from the Interpreters’ Standpoint. In: Gyde Hansen, Kirsten MalmkjÆr and Daniel Gile, eds. Claims, 
Changes and Challenges in Translation Studies: Selected Contributions from the EST Congress, Copenhagen 2001. Amsterdam: John Benjamins, 239-249.

Bontempo, Karen and Napier, Jemina (2007): Mind the Gap!: A Skills Analysis of Sign Language Interpreters. The Sign Language Translator and Interpreter. 1(2):275-299.

Chang, Chia-chien and Schallert, Diane L. (2007): The Impact of Directionality on Chinese/ English Simultaneous Interpreting. Interpreting. 9(2):137-176.

CHoI, Jungwha (2008): Correlation between Directionality, B Language Acquisition and Topic Difficulty. Forum. 6(2):39-58.

Christoffels, Ingrid K., De Groot, Annette M. B. and Kroll, Judith F. (2006): Memory and Language Skills in Simultaneous Interpreters: The Role of Expertise and Language Proficiency. Journal of Memory and Language. 54(3):324-345.

Daro, Valeria, Lambert, Sylvie and Fabbro, Franco (1996): Conscious Monitoring of Attention during Simultaneous Interpretation. Interpreting. 1(1):101-124.

DE Bot, Kees (2000): Simultaneous Interpreting as Language Production. In: Birgitta Englund Dimitrova and Kenneth Hyltenstam, eds. Language Processing and Simultaneous Interpreting: Interdisciplinary Perspectives. Amsterdam: John Benjamins, 65-88.

Denissenko, Jurij (1989): Communicative and Interpretative Linguistics. In: Laura Gran and John Dodns, eds. The Theoretical and Practical Aspects of Teaching Conference Interpretation. Udine: Campanotto, 155-157.

Donovan, Clare (2004): European Masters Project Group: Teaching Simultaneous Interpretation into a B Language. Preliminary Findings. Interpreting. 6(2):205-216.

Donovan, Clare (2005): Teaching Simultaneous Interpretation into B: A Challenge for Responsible Interpreter Training. In: Rita Godijns and Michaël Hinderdael, eds. Directionality in Interpreting: The "Retour" or the Native?. Ghent: Communication and Cognition, 147-165.

GaIBA, Francesca (1999): Interpretation at the Nuremberg Trial. Interpreting. 4(1):9-22.

GiLE, Daniel (2005): Directionality in Conference Interpreting: A Cognitive View. In: Rita Godijns and Michaël Hinderdael, eds. Directionality in Interpreting: The "Retour" or the Native? Ghent: Communication and Cognition, 9-26.

GiLe, Daniel (1995/2009): Basic Concepts and Models for Interpreter and Translator Training. $2^{\text {nd }}$ ed. Amsterdam: John Benjamins.

Godijns, Rita and Hinderdael, Michaël, eds. (2005): Directionality in Interpreting: The "Retour" or the Native? Ghent: Communication and Cognition.

Goswell, Della (2011): Being There: Role Shift in English to Auslan Interpreting. In: Lorraine Leeson, Svenja Wurm and Myriam Vermeerbergen, eds. Signed Language Interpreting: Preparation, Practice and Performance. Manchester: St. Jerome, 61-86.

Hauser, Angela B. and Hauser, Peter C. (2008): The Deaf Professional-Designated Interpreter Model. In: Peter C. Hauser, Karen L. Finch and Angela B. Hauser, eds. Deaf Professionals and Designated Interpreters: A New Paradigm. Washington, D.C.: Gallaudet University Press, 3-21.

Hauser, Peter C., Finch, Karen L. and Hauser, Angela B., eds. (2008): Deaf Professionals and Designated Interpreters: A New Paradigm. Washington, D.C.: Gallaudet University Press.

Hild, Adelina (2006): Review of: Godijns, Rita and Hinderdael, Michaël, eds. (2005): Directionality in Interpreting: The "Retour" or the Native? Ghent: Communication and Cognition, 197 p. Interpreting. 8(2):223-229.

Hurwitz, T. Alan (2008): Foreword. In: Peter C. Hauser, Karen L. Finch and Angela B. Hauser, eds. Deaf Professionals and Designated Interpreters: A New Paradigm. Washington, D.C.: Gallaudet University Press, vii-x.

Johnston, Trevor and Schembri, Adam (2007): Australian Sign Language (Auslan): An Introduction to Sign Language Linguistics. Cambridge: Cambridge University Press.

Kalina, Sylvia (2005): Quality in the Interpreting Process: What Can be Measured and How? In: Rita Godijns and Michaël Hinderdael, eds. Directionality in Interpreting: The "Retour" or the Native?. Ghent: Communication and Cognition, 27-46. 
Kellett Bidoli, Cynthia Jane (2002): Spoken-language and signed-language interpretation: Are they really so different? In: Giuliana Garzone and Maurizio ViezzI, eds. Interpreting in the 21st Century: Challenges and Opportunities. Amsterdam: John Benjamins, 171-179.

Kroll, Judith F. and Stewart, Erika (1994): Category Interference in Translation and Picture Naming: Evidence for Asymmetric Connections between Bilingual Memory Representations. Journal of Memory and Language. 33(2):149-174.

Lim, Hyang-Ok (2005): Working into the B Language: The Condoned Taboo? Meta. 50(4).

Martin, Ann (2005): Interpreting from A to B: A Spanish Case Study. In: Rita Godijns and Michaël Hinderdael, eds. Directionality in Interpreting: The "Retour" or the Native? Ghent: Communication and Cognition, 83-99.

McNamara, Tim (2000): Language Testing. Oxford: Oxford University Press.

Metzger, Melanie (2006): Salient Studies of Signed Language Interpreting in the Context of Community Interpreting Scholarship. Linguistica Antverpiensia. 5:263-291.

NAPIER, Jemina (2002): Sign Language Interpreting: Linguistic Coping Strategies. Coleford: Douglas McLean.

NAPIER, Jemina (2006): Comparing Language Contact Phenomena between Auslan-English Interpreters and Deaf Australians: A Preliminary Study. In: Ceil LucAs, ed. Multilingualism and Sign Languages: From the Great Plains to Australia. Washington: Gallaudet University Press, 39-77.

NAPIER, Jemina (2011): Signed Language Interpreting. In: Kirsten MaLmKJÆR and Kevin WindLE, eds. The Oxford Handbook of Translation Studies. Oxford: Oxford University Press, 357-376.

NAPIER, Jemina and BArker, Roz (2003): A demographic survey of Australian Sign Language Interpreters. Australian Journal of Education of the Deaf. 9:19-32.

Napier, Jemina, Carmichael, Andy and Wiltshire, Andrew (2008): Look-Pause-Nod: A Linguistic Case Study of A Deaf Professional and Interpreters Working Together. In: Peter C. Hauser, Karen L. Finch and Angela B. Hauser, eds. Deaf Professionals and Designated Interpreters: A New Paradigm. Washington, D.C.: Gallaudet University Press, 22-42.

NAPIER, Jemina, McKee, Rachel and Goswell, Della (2006/2010): Sign Language Interpreting: Theory and Practice in Australia and New Zealand. $2^{\text {nd }}$ ed. Sydney: The Federation Press.

Napier, Jemina, Rohan, Meg and Slatyer, Helen (2005): Perceptions of Bilingual Competence and Preferred Language Direction in Auslan/English Interpreters. Journal of Applied Linguistics. 2(2):185-218.

Nicodemus, Brenda (2011): Does Language Direction Preference Match Interpreting Proficiency? An Examination of Novice and Expert Interpreters, unpublished. Presented at Gallaudet University, Washington, D.C., 29 November 2011.

Nicodemus, Brenda and Emmorey, Karen (2013): Direction Asymmetries in Spoken and Signed Language Interpreting. Bilingualism: Language and Cognition. 16(3):624-636.

Padilla, Presentación (2005): Cognitive Implications of the English-Spanish Direction for the Quality and the Training of Simultaneous Interpreting. In: Rita GodıjNs and Michaël Hinderdael, eds. Directionality in Interpreting: The "Retour" or the Native?. Ghent: Communication and Cognition, 47-62.

PAvlović, Nataša (2007): Directionality in Translation and Interpreting Practice: Report on a Questionnaire Survey in Croatia. Forum. 5(2):79-99.

PöchнаскеR, Franz (2004): Introducing Interpreting Studies. London: Routledge.

Russell, Debra and MALCOLM, Karen (2009): Assessing ASL-English Interpreters: The Canadian Model of National Certification. In: Claudia V. Angelelli and Holly E. JacoBson, eds. Testing and Assessment in Translation and Interpreting Studies. Amsterdam: John Benjamins, 331-376.

Schembri, Adam, Johnston, Trevor and Goswell, Della (2006): NAME Dropping: Location Variation in Australian Sign Language. In: Ceil Lucas, ed. Multilingualism and Sign Languages: From the Great Plains to Australia. Washington, D.C.: Gallaudet University Press, 121-156. 
Schembri, Adam, McKee, David, McKee, Rachel et al. (2009): Phonological Variation and Change in Australian and New Zealand Sign Language: The Location Variable. Language Variation and Change. 21(2):193-231.

SEeL, Olaf-Immanuel (2005): Non-Verbal Means as Culture-Specific Determinants that Favour Directionality into the Foreign Language in Simultaneous Interpreting. In: Rita Godijns and Michaël Hinderdael, eds. Directionality in Interpreting: The "Retour" or the Native?. Ghent: Communication and Cognition, 63-82.

Seleskovitch, Danica (1978): Interpreting for International Conferences: Problems of Language and Communication. Washington: Pen and Booth.

TAYLOR, Marty M. (1993): Interpretation Skills: English to American Sign Language. Edmonton: Interpreting Consolidated.

TAYLOR, Marty M. (2002): Interpretation Skills: American Sign Language to English. Edmonton: Interpreting Consolidated.

Tommola, Jorma and Helevë, Marketta (1998): Language Direction and Source Text Complexity: Effects on Trainee Performance in Simultaneous Interpreting. In: Lynne Bowker, Michael Cronin, Dorothy Kenny et al., eds. Unity in Diversity? Current Trends in Translation Studies. Manchester: St. Jerome, 177-186.

Tommola, Jorma and LaAkso, Tiina (1997): Source-Text Segmentation, Speech Rate and Language Direction: Effects on Trainee Simultaneous Interpreting. In: Kinga KLAUdy and János KoHn, eds. Transferre Necesse Est. Proceedings of the Second International Conference on Current Trends in Studies of Translation and Interpreting. Budapest: Scholastica, 186-191.

van Dijk, Rick, Boers, Eveline, Christoffels, Ingrid et al. (2011): Directionality Effects in Simultaneous Language Interpreting: The Case of Sign Language Interpreters in the Netherlands. American Annals of the Deaf. 156(1):47-55.

XIAO, Xiaoyan and Yu, Ruiling (2009): Survey on Sign Language Interpreting in China. Interpreting. 11(2):137-163.

APPENDIX

Pseudonyms and educational/professional details of participants

\begin{tabular}{|c|c|c|c|c|c|c|c|}
\hline \multicolumn{4}{|c|}{ Native signers $(\mathrm{N}=14)$} & \multicolumn{4}{|c|}{ Non-native signers $(\mathrm{N}=17)$} \\
\hline Pseudonym & $\begin{array}{l}\text { University } \\
\text { qualification }\end{array}$ & $\begin{array}{l}\text { Interpreter } \\
\text { education }\end{array}$ & $\begin{array}{c}\text { Years of } \\
\text { interpreting } \\
\text { experience }\end{array}$ & Pseudonym & $\begin{array}{l}\text { University } \\
\text { qualification }\end{array}$ & $\begin{array}{l}\text { Interpreter } \\
\text { education }\end{array}$ & $\begin{array}{c}\text { Years of } \\
\text { interpreting } \\
\text { experience }\end{array}$ \\
\hline Alex & Undergrad & None & 23 & Bernie & Undergrad & A & 20 \\
\hline Amber & None & $\mathrm{A}$ & 3 & Claire & Postgrad & None & 25 \\
\hline Annie & Postgrad & $\mathrm{A}, \mathrm{C}$ & 15 & Debbie & $\mathrm{PhD}$ & None & 27 \\
\hline Charlie & None & A & 3 & Dorothy & Postgrad & $\mathrm{A}, \mathrm{C}$ & 15 \\
\hline Cynthia & None & None & 27 & Helen & Postgrad & A & 21 \\
\hline Emily & None & None & 14 & Jane & $\mathrm{PhD}$ & $\mathrm{A}, \mathrm{C}$ & 5 \\
\hline Lauren & None & A & 3 & Jennifer & Undergrad & None & 4 \\
\hline Kay & Postgrad & None & 25 & Linda & Postgrad & $\mathrm{A}, \mathrm{C}$ & 6 \\
\hline Monica & None & A & 12 & $\mathrm{Liz}$ & Undergrad & A & 9 \\
\hline Rachael & Postgrad & None & 23 & Mary & Postgrad & $\mathrm{C}$ & 13 \\
\hline Sam & None & $\mathrm{A}, \mathrm{B}$ & 15 & Miranda & Postgrad & $\mathrm{A}, \mathrm{C}$ & 8 \\
\hline Shannon & Postgrad & $\mathrm{A}, \mathrm{C}$ & 14 & Molly & Postgrad & $A, C$ & 18 \\
\hline Tiffany & None & None & 22 & Rose & Postgrad & $\mathrm{C}$ & 15 \\
\hline \multirow[t]{4}{*}{ Zoe } & Postgrad & $\mathrm{C}$ & 24 & Sabrina & None & A & 9 \\
\hline & & & & Sophia & None & A & 10 \\
\hline & & & & Vicky & None & A, B & 11 \\
\hline & & & & Wendy & Postgrad & $\mathrm{A}, \mathrm{C}$ & 18 \\
\hline
\end{tabular}

Note. A: Diploma of Interpreting (Auslan/English); B: Advanced Diploma of Interpreting (Auslan/English); C: Postgraduate Diploma in Auslan/English Interpreting or equivalent. 